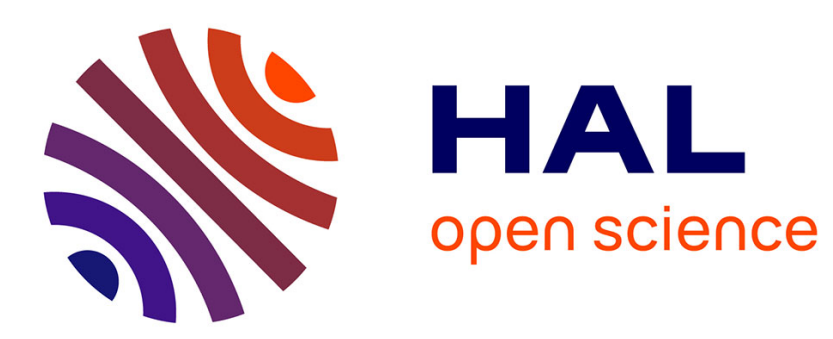

\title{
Borrowing Constraints and Complex Dynamics in an OLG Framework
}

Tiziana Assenza, Anna Agliari, Domenico Delli Gatti, Emiliano Santoro

\section{To cite this version:}

Tiziana Assenza, Anna Agliari, Domenico Delli Gatti, Emiliano Santoro. Borrowing Constraints and Complex Dynamics in an OLG Framework. Journal of Economic Behavior and Organization, 2009, 72 (2), pp.656. 10.1016/j.jebo.2009.07.011 . hal-00723003

\section{HAL Id: hal-00723003 https://hal.science/hal-00723003}

Submitted on 7 Aug 2012

HAL is a multi-disciplinary open access archive for the deposit and dissemination of scientific research documents, whether they are published or not. The documents may come from teaching and research institutions in France or abroad, or from public or private research centers.
L'archive ouverte pluridisciplinaire HAL, est destinée au dépôt et à la diffusion de documents scientifiques de niveau recherche, publiés ou non, émanant des établissements d'enseignement et de recherche français ou étrangers, des laboratoires publics ou privés. 


\section{Accepted Manuscript}

Title: Borrowing Constraints and Complex Dynamics in an OLG Framework

Authors: Tiziana Assenza, Anna Agliari, Domenico Delli

Gatti, Emiliano Santoro

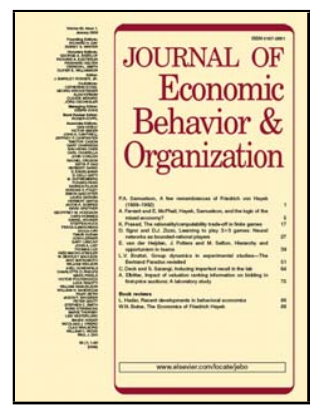

PII:

S0167-2681(09)00190-5

DOI: doi:10.1016/j.jebo.2009.07.011

Reference: JEBO 2427

To appear in: Journal of Economic Behavior \& Organization

Received date: $\quad$ 20-10-2008

Revised date: $\quad 25-7-2009$

Accepted date: $\quad$ 27-7-2009

Please cite this article as: Assenza, T., Agliari, A., Gatti, D.D., Santoro, E., Borrowing Constraints and Complex Dynamics in an OLG Framework, Journal of Economic Behavior and Organization (2008), doi:10.1016/j.jebo.2009.07.011

This is a PDF file of an unedited manuscript that has been accepted for publication. As a service to our customers we are providing this early version of the manuscript. The manuscript will undergo copyediting, typesetting, and review of the resulting proof before it is published in its final form. Please note that during the production process errors may be discovered which could affect the content, and all legal disclaimers that apply to the journal pertain. 


\title{
Borrowing Constraints and Complex Dynamics in an OLG Framework*
}

\author{
Tiziana Assenza ${ }^{a, b}$, Anna Agliari ${ }^{c}$, \\ Domenico Delli Gatti ${ }^{a}$, Emiliano Santoro ${ }^{d, e}$ \\ ${ }^{a}$ Catholic University of Milan, Italy ${ }^{b}$ CeNDEF, University of Amsterdam, The Netherlands \\ ${ }^{c}$ Catholic University of Piacenza, Italy \\ $d_{\text {Department of Economics and EPRU, University of Copenhagen, Denmark }}$ \\ ${ }^{e}$ CIFREM, University of Trento, Italy
}

July 25, 2009

\begin{abstract}
In this paper we model an OLG economy à la Kiyotaki and Moore whose novel feature is the role of money as a store of value and of bequest as a source of funds to be "invested" in landholding. The dynamics generated by the model are generally characterized by irregular cyclical trajectories and, under special configuration of the parameters, a strange attractor appears. In this setting, an expansionary monetary policy may have a stabilizing role due to the interaction between money holding and the accumulation of borrowers' net worth.
\end{abstract}

JEL codes: E32; E52

Keywords: Borrowing constraints; Credit cycles; Complex dynamics, Monetary policy.

${ }^{*}$ Corresponding author: Tiziana Assenza, ITEMQ, Catholic University of Milan, via Necchi 5, 20123 Milan, Italy. e-mail: tiziana.assenza@unicatt.it; 


\section{Introduction}

According to the traditional view of the monetary transmission mechanism, in the long run an increase in the growth rate of money supply translates into an increase in inflation which has no real effects under the assumptions of perfect capital markets, dynastic households and lump-sum taxes. A large empirical literature has shown, on the contrary, that the inflation rate could affect real activity leading to an increase in savings, output or the capital stock (Loayza et al. 2000, Bullard and Keating, 1995, Khan et al., 2001). An intuitive but controversial explanation of this fact is the Tobin-Mundell effect: in a simplified economy in which money and capital are substitutes in households' portfolio, an increase of the inflation rate lowers the rate of return on money and yields a shift away from money and towards greater holdings of productive capital. Recently, different explanations of monetary non - neutrality in a more realistic setting have been put forward: the long run real effects of monetary policy are traced back to the redistribution of seigniorage rents across households (Grandmont and Younès,1973, Kehoe et al., 1992) or across generations (Weiss, 1980 ; Weil, 1991). The long run real effects of inflation have been detected also in models with financial market imperfections. Boyd and Smith (1998) study this issue in a setting of multiple equilibria. Cordoba and Ripoll (2004) focus on the persistence of monetary policy shocks in a framework with credit constraints. Ragot (2006) explores the relation between the severity of credit constraints and long run inflation in a monetary growth model.

The present paper can be classified, for the sake of simplicity, in this body of literature. We explore, however, a new channel of monetary nonneutrality in the presence of financial frictions. When agents face a borrowing constraint, a redistribution of real assets can occur due to the interaction between net worth and inflation. In other words a change in the growth rate

of money supply can affect real output through the impact of inflation on borrowers' net worth. 
In order to analyze this channel we develop an overlapping generation version of a Kiyotaki and Moore (1997) economy (KM hereafter). To the best of our knowledge, no other attempt has been made to develop an OLG framework of a KM economy with the exception of Kasa (1998) who presents an OLG variant of the KM model in a Blanchard-Yaari "finite horizon" framework (Blanchard, 1985).

We model an OLG-KM economy à la Diamond-Samuelson with money and bequest. We assume that real money balances yield liquidity services and enter the utility function (a standard assumption since Weiss, 1980). In our framework money is essentially a store of value, which allows increased consumption and bequest when old.

The endogenous dynamics generated by the OLG-KM model are much richer than those of the original framework. In the present model, in fact, trajectories can converge to a steady state or to periodic or aperiodic cyclical patterns, i.e. to credit cycles properly speaking, and eventually, under specific parameter constellation, a strange attractor emerges. Strictly speaking the original KM model generates credit fluctuations (i.e. fluctuations sparked by a productivity shock and propagated by the impact of asset price changes on the availability of credit) instead of credit cycles (i.e. endogenously determined oscillating behavior).

The paper is organized as follows. Section 2 describes the basic features and the behavioral assumption of our OLG-KM economy. The analytical details of the optimization problems are confined in the appendix. Section 3 is devoted to an analysis of the resource constraint and money flows. In Section 4 we discuss the dynamics of the model. Section 5 is devoted to a comparison with the baseline KM framework. Section 6 concludes. 


\section{An OLG-KM Economy}

In an OLG-KM economy, four classes of agents coexist at each point in time. In order to simplify matters, we normalize the population in each class to unity so that we will deal in the following with a young farmer (YF), an old farmer $(\mathrm{OF})$, a young gatherer (YG) and an old gatherer (OG).

There are two types of good, output ("fruit") - denoted by $y$ - and a non-reproducible asset ("land") - denoted by $K$ - whose total supply is fixed $(\bar{K})$. Following KM we assume that output is produced by means of a technology which uses land and labour and yields output with a one period lag. Due to the particular timing of an OLG economy, it is straightforward to assume therefore that each agent applies labour to production when young and obtains the fruit of this effort when old.

Each young agent is endowed with one unit of labour. By assumption farmers and gatherers have access to different technologies. The production function of the YF is $y_{t}^{F}=\alpha K_{t-1}^{F}, \alpha>0$, while the production function of the $\mathrm{YG}$ is $y_{t}^{G}=G\left(K_{t-1}^{G}\right)$. Function $G($.$) is increasing and strictly concave in$ its argument, and satisfies the usual Inada conditions. Due to the time lag between cultivation and production, the agents work when young and obtain fruit when old.

For the sake of simplicity we assume that young agents postpone consumption. Moreover, they leave a bequest to the offspring when old. As usual the bequest motive is rooted in intergenerational altruism. We assume also that money provides specific utility to the young agent. The generic utility function therefore is:

$$
U^{i}=U\left(c_{t, t+1}^{i}, a_{t+1}^{i}, m_{t, t}^{i}\right) \quad i=F, G
$$

where $c_{t, t+1}^{i}$ is consumption of the agent of type $i$ and generation $t$ in $t+1$ (the

old agent), $a_{t+1}^{i}$ is bequest left by the same agent to his/her child, $m_{t, t}^{i}:=\frac{M_{t, t}^{i}}{P_{t}}$ are real money balances of the agent of type $i$ and generation $t$ in $t$ (the young 
agent).

\subsection{The Farmer/Borrower}

The farmer maximizes $U^{F}=u\left(c_{t+1}^{F}, a_{t+1}^{F}, m_{t, t}^{F}\right)$ subject to three constraints: the flow-of-funds constraint when young, the flow-of-funds constraint when old and the financing constraint.

The flow-of-funds constraint of the young farmer in $t$ (in real terms) is:

$$
q_{t}\left(K_{t}^{F}-K_{t-1}^{F}\right)+m_{t, t}^{F} \leq b_{t}+a_{t}^{F}
$$

where $q_{t}:=\frac{Q_{t}}{P_{t}}$ is the real price of land; $m_{t, t}^{F}=\frac{M_{t, t}^{F}}{P_{t}}$ are the YF's real money balances, $b_{t}$ is credit and $a_{t}^{F}$ is bequest, i.e. wealth inherited by the YF. According to (1), the resources of the YF, of internal or external origin $\left(a_{t}^{F}\right.$ and $b_{t}$ respectively), can be employed to "invest" $q_{t}\left(K_{t}^{F}-K_{t-1}^{F}\right)$ - i.e. to change the farmer's landholding - and accumulate money balances $m_{t, t}^{F}$.

Since the young does not derive utility from consumption, the YF carries money over from youth to old age in order to use it as a means of payment in the second stage of his life. Notice that the old agent can consume (and leave as a bequest) the output obtained from working when young - net of interest payments to the gatherer - because it takes one period for land to bear fruit. Strictly speaking money is not absolutely necessary to make consumption possible when old. Money only allows to increase consumption (and bequest) when old over and above the level made possible by production alone.

The YF borrows from the YG. Being endowed with inalienable human capital, the former can get a loan equal at most to the value of collateralizable assets, i.e. the future value of the land he/she is currently owning. The financing constraint can be expressed as:

$$
b_{t} \leq \frac{q_{t+1}}{R} K_{t}^{F}
$$


where $R$ is the real (gross) interest rate and $q_{t+1}$ is the real price of land in the future which we assume is known in advance (perfect foresight).

In period $t$, the young farmer uses labour and land $K_{t}^{F}$ to produce output which will become available in $t+1$. When old, the farmer's resources $e_{t+1}^{F}$ consist of output $y_{t+1}^{F}=\alpha K_{t}^{F}$ and real money balances $m_{t, t+1}^{F}=\frac{M_{t, t+1}^{F}}{P_{t+1}}$ less debt service $R b_{t}$ i.e. $e_{t+1}^{F}=\alpha K_{t}^{F}+m_{t, t+1}^{F}-R b_{t}$. These resources can be employed to consume and leave a bequest:

$$
c_{t, t+1}^{F}+a_{t+1}^{F}+R b_{t} \leq \alpha K_{t}^{F}+m_{t, t+1}^{F}
$$

We conceive of money injections as monetized transfers from the public sector to the old agents. Therefore nominal money balances of the farmer when old $M_{t, t+1}^{F}$ are equal to the sum of money carried on from youth $M_{t, t}^{F}$ and of subsidies $T_{t+1}^{F}$. Moreover, we assume that these transfers are proportional to money balances in youth, i.e. $T_{t+1}^{F}=g_{M} M_{t, t}^{F}$. Hence $M_{t, t+1}^{F}=$ $M_{t, t}^{F}\left(1+g_{M}\right)$, where $g_{M}$ is the rate of growth of money supply. It is straightforward to conclude that real money balances when old are:

$$
m_{t, t+1}^{F}=m_{t, t}^{F}\left(1+g_{M}\right) \theta_{t+1}
$$

where $\theta_{t+1}:=\frac{P_{t}}{P_{t+1}}$ is the real return on money. ${ }^{1}$

From the FOCs of the optimization problem we conclude that the financing constraint will be binding if the following condition holds true:

$$
u_{m}>u_{c} R
$$

where $u_{m}=\frac{\partial u}{\partial m_{t, t}^{F}}$ and $u_{c}=\frac{\partial u}{\partial c_{t, t+1}^{F}}$ are the marginal utilities of money and

\footnotetext{
${ }^{1}$ Of course $\theta_{t+1}=\frac{1}{1+\pi_{t+1}}$, where $\pi_{t+1}$ is the inflation rate.
} 
consumption (when old). ${ }^{2}$

Suppose the young farmer obtains a new loan consisting of one unit of fruit and increases money holding in period $t$ by the same amount. ${ }^{3}$ In our setting additional money yields an increase in utility both in youth and in old age. This effect is captured by the $u_{m}$ term. Hence the LHS of (4) is the total increase in utility due to an increase in money holding by one unit when the farmer is young.

Then, the farmer has to pay back $R>1$ units of fruit to the gatherer. The marginal utility of future consumption the old farmer should give up therefore is $\frac{\partial u}{\partial c_{t, t+1}^{F}} \frac{\partial c_{t, t+1}^{F}}{\partial b_{t}}=u_{c} R$. Inequality (4) states that the financing constraint is binding if the marginal utility $u_{m}$ the farmer obtains from increasing money holding by one unit as a consequence of increasing debt by the same amount when young is greater than the marginal utility of consumption $u_{c} R$ the farmer should give up because he has to reimburse debt when old. In this case the farmer has an incentive to get as much debt as he can.

Notice that from (4) if there were no effect on utility of money holding when young, i.e. $u_{m}=0$, the condition for a binding financing constraint would never be satisfied because $u_{c} R>0$. A necessary condition for money to be held in portfolios by rational farmers when young, therefore, is $u_{m}>0$. This is the reason why money shows up in the utility function. Thanks to this feature we can incorporate our framework in to the class of OLG models with Money in the Utility Function (Weiss, 1980).

When the constraints turn out to be binding, as we will assume, by substituting (2) into (1) and rearranging one gets:

$$
\mu_{t} K_{t}^{F}=a_{t}^{F}+q_{t} K_{t-1}^{F}-m_{t, t}^{F}
$$

\footnotetext{
${ }^{2}$ The marginal utility of bequest $u_{a}=\frac{\partial u}{\partial a_{t+1}^{F}}$ is equal to the marginal utility of consumption.

${ }^{3}$ By assumption consumption when young does not yield utility. Therefore, the additional loan is not consumed.
} 
where $\mu_{t}=q_{t}-\frac{q_{t+1}}{R}$ is the downpayment, i.e. the internal funds the YF must provide (together with external funds, i.e. the loan extended by the YG) to purchase land. The RHS of equation (5) represents the farmer's net worth - consisting of bequest and the market value of land net of money balances. According to (5) the farmer accumulates net worth to provide the downpayment necessary to increase his landholding.

If the YF did not hold money, he could accumulate more net worth, provide a higher downpayment and obtain more land. Money holdings exert a crowding out effect on investment in land.

Substituting (2) into (3) and rearranging one gets:

$$
c_{t, t+1}^{F}+a_{t+1}^{F}=\left(\alpha-q_{t+1}\right) K_{t}^{F}+m_{t, t+1}^{F} .
$$

Money carried over from young age increases resources of the old farmer. The effort to put aside money when young pays off in old age because it adds resources to those already available to the old for consumption and bequest. The RHS of $(6)$, i.e. $\left(\alpha-q_{t+1}\right) K_{t}^{F}+m_{t, t+1}^{F}$ is the equation of the resources of the old $\left(e_{t+1}^{F}\right){ }^{4}$

For simplicity we assume that the utility function is separable and adopt a Cobb-Douglas specification for consumption and bequest and a linear specification for money in the utility function:

$$
U^{F}=\gamma \ln c_{t, t+1}^{F}+(1-\gamma) \ln a_{t+1}^{F}+\nu^{F} m_{t, t}^{F}
$$

where $0<\gamma<1, \nu^{F}>0$. The farmer maximizes (7) subject to (1), (2) and (3). It turns out that for the optimal solution all constraints are binding (see the appendix).

From the FOCs and the constraints it is easy to conclude that, due to

\footnotetext{
${ }^{4}$ We impose

$$
\alpha K_{t}^{F}+m_{t, t+1}^{F}>q_{t+1} K_{t}^{F}
$$

to assure non negativity of $e_{t+1}^{F}$.
} 
the Cobb-Douglas specification of preferences, consumption and bequest are a fraction $\gamma$ and $1-\gamma$ respectively of the resources available in $t+1$ to the $\mathrm{OF}: c_{t, t+1}^{F}=\gamma e_{t+1}^{F}$ and $a_{t+1}^{F}=(1-\gamma) e_{t+1}^{F}$. Hence:

$$
\begin{gathered}
c_{t, t+1}^{F}=\gamma\left[\left(\alpha-q_{t+1}\right) K_{t}^{F}+m_{t, t+1}^{F}\right], \\
a_{t+1}^{F}=(1-\gamma)\left[\left(\alpha-q_{t+1}\right) K_{t}^{F}+m_{t, t+1}^{F}\right] .
\end{gathered}
$$

Moreover $u_{m}=\nu^{F}$ and $u_{c}=\frac{\gamma}{c_{t, t+1}^{F}}=\frac{1}{e_{t+1}^{F}}$ since $c_{t+1}^{F}=\gamma e_{t+1}^{F}$. Hence (4) specializes to:

$$
\nu^{F}>\frac{R}{e_{t+1}^{F}} .
$$

In words, the (constant) marginal utility of money should be greater than a threshold level which in turn is a function, among other things, of the price of land, the farmer's landholding and the old farmer's money balances (see appendix for details).

From (9) it follows that the optimal bequest of the OF of generation $t-1$ in $t$ is:

$$
a_{t}^{F}=(1-\gamma)\left[\left(\alpha-q_{t}\right) K_{t-1}^{F}+m_{t-1, t}^{F}\right],
$$

where $m_{t-1, t}^{F}=\frac{M_{t-1, t}^{F}}{P_{t}}$ are real money balances of the OF of generation $t-1$ in $t$. After substituting this expression in (5) one gets:

$$
\mu_{t} K_{t}^{F}=\left[(1-\gamma) \alpha+\gamma q_{t}\right] K_{t-1}^{F}+(1-\gamma) m_{t-1, t}^{F}-m_{t, t}^{F}
$$

which is the law of motion of the land of the farmer.

The RHS of (10) represents the YF's net worth, which turns out to depend on total output $\alpha K_{t-1}^{F}$, on the market value of land $q_{t} K_{t-1}^{F}{ }^{5}$ and on money

\footnotetext{
${ }^{5}$ Due to the financing constraint, the market value of land is equal to debt service $q_{t} K_{t-1}^{F}=R b_{t-1}$. The higher the market value, therefore, the higher will be the interest payments for the OF and the lower resources and bequest. This effect, albeit only indirect, is detrimental for the YF's net worth. On the other hand, by definition, the market value of inherited landholding directly affects the YF's net worth. This latter effect more than
} 
balances $m_{t-1, t}^{F}$ and $m_{t, t}^{F}$. Money has two different and contrasting effects on net worth (and therefore on landholding):

1. given the bequest, the higher is money of the young $m_{t, t}^{F}$, the lower net worth and landholding. In fact resources of the young (bequest and credit) can be devoted either to money or landholding;

2. the higher is money of the old $m_{t-1, t}^{F}$, the higher resources available to him and the higher the bequest the old leaves to the young. This bequest, in turn, is a component of net worth which can be employed by the young to expand landholding.

At this stage of the analysis, it is not clear which effect prevails. In the following (see section 3) we will derive a condition which must be satisfied for the negative effect $(\# 1)$ to prevail over the positive effect $(\# 2)$.

\subsection{The Gatherer/Lender}

Being unconstrained from a financial point of view, the gatherer maximizes $U^{G}=u\left(c_{t+1}^{G}, a_{t+1}^{G}, m_{t, t}^{G}\right)$ subject to the sole sequence of flow of funds constraints. The flow of funds constraint of the young gatherer in $t$ reads as:

$$
m_{t, t}^{G}+b_{t}+q_{t}\left(K_{t}^{G}-K_{t-1}^{G}\right) \leq a_{t}^{G}
$$

According to (11), the resources of the $\mathrm{YG}$, which coincide with bequest $\left(a_{t}^{G}\right)$, can be employed to "invest", $q_{t}\left(K_{t}^{G}-K_{t-1}^{G}\right)$, extend credit and hold money balances. If the YG did not put aside some money in order to employ it in the future - i.e. to increase his resources when old - he could invest more in land or lend more.

offsets the former one so that in the end the market value of land turns out to be a positive component of the YF's net worth, with a weight $\gamma$ smaller than one. 
In $t$, the YG uses labour and land $K_{t}^{G}$ to produce output which will become available in $t+1: y_{t+1}^{G}=G\left(K_{t}^{G}\right)$. When old, the gatherer's resources consist of output (produced when young), interest payments received from the farmer and money balances: $e_{t+1}^{G}=G\left(K_{t}^{G}\right)+R b_{t}+m_{t, t+1}^{G}$. These resources can be employed to consume and leave a bequest. We assume, however, that part of the money carried over from youth $C M F_{t}^{G}=\varphi M_{t, t}^{G}$, $0<\varphi<1$ is kept as a buffer stock to carry on the lending business "smoothly". The gatherer, in fact, in this context (as in KM) plays the role of the lender. We can think of $\varphi$ as a policy parameter, possibly established by the central bank in his role of regulator/supervisor of the banking system or as a rough measure of transaction cost due to "financial frictions".

Therefore the flow of funds constraint of the OG in $t+1$ in real terms is:

$$
c_{t, t+1}^{G}+a_{t+1}^{G}+C M F_{t}^{G} \leq G\left(K_{t}^{G}\right)+R b_{t}+m_{t, t+1}^{G} .
$$

From the FOCs one gets:

$$
\frac{G^{\prime}\left(K_{t}^{G}\right)}{R}=q_{t}
$$

The interpretation of (13) is as follows. Suppose the young gatherer sells one unit of land in $t$ at the price $q_{t}$. The young farmer's landholding increases by one unit so that the loan the gatherer extends to the farmer goes up by $q_{t+1} / R$. All in all, the increase of resources available to the gatherer when young is equal to $q_{t}-\left(q_{t+1} / R\right)=\mu_{t}$, i.e. the downpayment. The marginal impact of this increase of resources in $t$ on the gatherer's utility is $u_{c} R\left[q_{t}-\left(q_{t+1} / R\right)\right]=u_{c}\left(R q_{t}-q_{t+1}\right)$.

The reduction in the gatherer's landholding in $t$ translates into a loss of output $G^{\prime}\left(K_{t}^{G}\right)$ in $t+1$. The loan made in $t$ yields interest payments equal to $R\left(q_{t+1} / R\right)=q_{t+1}$. Therefore, selling one unit of land in $t$ leads to a reduction of resources in $t+1$ equal to $G^{\prime}\left(K_{t}^{G}\right)-q_{t+1}$. The marginal impact of this decrease of resources in $t+1$ on utility is $u_{c}\left[G^{\prime}\left(K_{t}^{G}\right)-q_{t+1}\right]$. In the optimum $u_{c}\left(R q_{t}-q_{t+1}\right)=u_{c}\left[G^{\prime}\left(K_{t}^{G}\right)-q_{t+1}\right]$. From this condition we get 
(13).

In order to save on notation, recalling that $K_{t}^{G}=\bar{K}-K_{t}^{F}$, we write $G^{\prime}\left(\bar{K}-K_{t}^{F}\right)=g\left(K_{t}^{F}\right)$, where $g^{\prime}=-G^{\prime \prime}>0$. Therefore we can re-write (13) as:

$$
q_{t}=\frac{g\left(K_{t}^{F}\right)}{R} .
$$

In the following we will refer to (14) as the asset price equation.

Following the same modelling strategy of the previous section, we assume that preferences of the gatherer are represented by:

$$
U^{G}=\gamma \ln c_{t, t+1}^{G}+(1-\gamma) \ln a_{t+1}^{G}+\nu^{G} m_{t, t}^{G}
$$

The gatherer maximizes $U^{G}$ subject to (11) and (12). All the constraints turn out to be binding (see the Appendix for further details).

Since the financing constraint is binding, the amount of credit extended by the $\mathrm{YG}$ in $t$ is $b_{t}=\frac{q_{t+1}}{R} K_{t}^{F}$. Therefore the resources of the old gatherer are $e_{t+1}^{G}=G\left(K_{t}^{G}\right)+q_{t+1} K_{t}^{F}+m_{t, t+1}^{G}-\varphi m_{t, t}^{G} \theta_{t+1}$. Using the FOCs and the constraints it is easy to conclude that consumption and bequest are a fraction $\gamma$ and $1-\gamma$ respectively of the resources available to the OG: $c_{t, t+1}^{G}=\gamma e_{t+1}^{G}$, $a_{t+1}^{G}=(1-\gamma) e_{t+1}^{G}$. Recalling that $m_{t, t+1}^{G}=m_{t, t}^{G}\left(1+g_{M}\right) \theta_{t+1}$ we get:

$$
\begin{gathered}
c_{t, t+1}^{G}=\gamma\left[G\left(K_{t}^{G}\right)+q_{t+1} K_{t}^{F}+m_{t, t+1}^{G}-\varphi m_{t, t}^{G} \theta_{t+1}\right], \\
a_{t+1}^{G}=(1-\gamma)\left[G\left(K_{t}^{G}\right)+q_{t+1} K_{t}^{F}+m_{t, t+1}^{G}-\varphi m_{t, t}^{G} \theta_{t+1}\right] .
\end{gathered}
$$

\section{Resource Constraints and Money Flows}

Since the total amount of land is fixed, an increase in landholding for the farmer can occur only if there is a corresponding decrease in landholding for the gatherer: $K_{t}^{F}-K_{t-1}^{F}=-\left(K_{t}^{G}-K_{t-1}^{G}\right)$. Taking this fact into account, summing side by side the flow of funds constraints of the young and the old 
agents (1), (11), (3) and (12) yields the aggregate resource constraint in $t+1$ :

$c_{t, t+1}^{F}+c_{t, t+1}^{G}+m_{t+1, t+1}^{F}+m_{t+1, t+1}^{G}=y_{t+1}^{F}+y_{t+1}^{G}+m_{t, t+1}^{G}+m_{t, t+1}^{F}-\varphi m_{t, t}^{G} \theta_{t+1}$,

where $y_{t+1}^{F}=\alpha K_{t}^{F}$ and $y_{t+1}^{G}=G\left(K_{t}^{G}\right)$. In words: the sum of aggregate output and real money balances of the old agents is equal to the sum of aggregate consumption of the old agents and real money balances of the young agents.

We assume equilibrium on the goods market, i.e.

$$
c_{t, t+1}^{F}+c_{t, t+1}^{G}=y_{t+1}^{F}+y_{t+1}^{G} .
$$

Taking (19) into account, (18) boils down to:

$$
m_{t+1, t+1}^{F}+m_{t+1, t+1}^{G}=m_{t, t+1}^{F}+m_{t, t+1}^{G}-\varphi m_{t, t}^{G} \theta_{t+1},
$$

i.e. the total amount of real money balances of the young agents is equal to the total amount of real money balances of the old agents.

In our economy money "trickles down" from one period to the next and from one agent to the other. In order to describe the way in which money flows in the economy, let's assume that $y_{t+1}^{F}-c_{t, t+1}^{F}=s_{t, t+1}^{F}>0$, i.e. the $\mathrm{OF}$ consumes less than the output he has produced. In a sense he is "saving" the amount $s_{t, t+1}^{F}$. Market clearing on the goods market implies $s_{t, t+1}^{G}=$ $-\left(c_{t, t+1}^{G}-y_{t+1}^{G}\right)=-s_{t, t+1}^{F}<0$ i.e. the OG consumes more than the output he has produced. He is "dissaving" the amount $\left(c_{t, t+1}^{G}-y_{t+1}^{G}\right)$.

The OF sells $s_{t, t+1}^{F}$ units of output to the OG in order to let him consume in excess of his output. The OG pays this output by means of money. Therefore, after the transaction, the OF has money balances equal to $m_{t, t+1}^{F}+$ $\left(c_{t, t+1}^{G}-y_{t+1}^{G}\right)$. This money is used to reimburse debt $b_{t} R$ to the $\mathrm{OG}$ and leave the bequest $a_{t+1}^{F}$ to the YF. The YF receives $a_{t+1}^{F}$ from $\mathrm{OF}$ and $b_{t+1}$ from the YG and employs these resources to invest, $q_{t+1}\left(K_{t+1}^{F}-K_{t}^{F}\right)$ and hold 
money balances.

Thanks to the Cobb-Douglas specification of the utility function, from the FOCs (see the Appendix) one gets:

$$
a_{t+1}^{i}=\frac{1-\gamma}{\gamma} c_{t, t+1}^{i} \quad i=F, G
$$

Assuming that $\xi:=\frac{m_{t, t}^{G}}{m_{t, t}^{F}}$ (i.e. the ratio of money of the gatherer to money of the farmer of the same generation is constant) and recalling that $m_{t, t+1}^{F}=$ $m_{t}^{F}\left(1+g_{M}\right) \theta_{t+1}$ we get:

$$
m_{t+1, t+1}^{F}=\frac{\left[\left(1+g_{M}\right)(1+\xi)-\varphi \xi\right] \theta_{t+1}}{1+\xi} m_{t, t}^{F} .
$$

After adjusting the time index and recalling that $m_{t-1, t}^{F}=m_{t-1, t-1}^{F}\left(1+g_{M}\right) \theta_{t}$ it is trivial to obtain the following relation between real money balances of the old farmer and of the young farmer:

$$
m_{t-1, t}^{F}=\frac{(1+\xi)\left(1+g_{M}\right)}{\left[\left(1+g_{M}\right)(1+\xi)-\varphi \xi\right]} m_{t, t}^{F}
$$

Substituting (22) in (10) the expression $(1-\gamma) m_{t-1, t}^{F}-m_{t, t}^{F}$ which shows up in (10) boils down to $-A m_{t}^{F}$ with:

$$
A=\frac{(1+\xi)\left(1+g_{M}\right) \gamma-\varphi \xi}{(1+\xi)\left(1+g_{M}\right)-\varphi \xi}
$$

We can plausibly assume that the cost parameter $\varphi$, albeit positive, is smaller than one. We can also safely assume that $0<\xi<1$. These are sufficient conditions for the denominator of the expression above to be positive. As a consequence, $A$ is positive if:

$$
(1+\xi)\left(1+g_{M}\right) \gamma>\varphi \xi
$$


i.e. if the preference parameter $\gamma$ is higher than a threshold $\bar{\gamma}=\varphi \xi /(1+\xi)\left(1+g_{M}\right)$. If this is the case, the negative effect of money holding on the farmer's net worth prevails over the positive one (see the end of section 2.1) and moneyholding act as a brake on investment in land. In the following we will consider only this scenario.

Therefore (10) simplifies to:

$$
K_{t}^{F}=\frac{\left[(1-\gamma) \alpha+\gamma q_{t}\right] K_{t-1}^{F}-A m_{t}^{F}}{\mu_{t}}
$$

Substituting (8) and (16) into the market clearing condition (19) we obtain:

$$
m_{t, t+1}^{G}+m_{t, t+1}^{F}-\varphi m_{t, t}^{G} \theta_{t+1}=\frac{1-\gamma}{\gamma}\left(y_{t+1}^{G}+y_{t+1}^{F}\right) .
$$

Equation (25) is the quantity theory of money in this context. Recalling equation (20) and that we have assumed $\xi:=\frac{m_{t, t}^{G}}{m_{t, t}^{F}}$ after substitutions and adjusting the time index (25) becomes:

$$
m_{t, t}^{F}=\frac{1-\gamma}{\gamma} \frac{1}{1+\xi}\left(y_{t}^{F}+y_{t}^{G}\right) .
$$

\section{Dynamics}

The dynamics of the macroeconomy are described by equation (24), i.e. the law of motion of the farmer's land, equation (14), i.e. the asset price equation, and equation (26), i.e. the quantity theory of money.

We list the equations below for the reader's convenience:

$$
\left\{\begin{array}{c}
K_{t}^{F}=\frac{\left[(1-\gamma) \alpha+\gamma q_{t}\right] K_{t-1}^{F}-A m_{t, t}^{F}}{\mu_{t}}, \\
q_{t}=\frac{g\left(K_{t}^{F}\right)}{R}, \\
m_{t, t}^{F}=\frac{1-\gamma}{\gamma} \frac{1}{1+\xi}\left[\alpha K_{t-1}^{F}+G\left(\bar{K}-K_{t-1}^{F}\right)\right] .
\end{array}\right.
$$


Plugging the third equation into the first one and recalling that $\mu_{t}=$ $q_{t}-\frac{q_{t+1}}{R}$, the law of motion of the farmer's land becomes:

$K_{t}^{F}=\frac{\left\{(1-\gamma) \alpha\left[1-\frac{A}{(1+\xi) \gamma}\right]+\gamma q_{t}\right\} K_{t-1}^{F}-(1-\gamma) \frac{A}{(1+\xi) \gamma} G\left(\bar{K}-K_{t-1}^{F}\right)}{q_{t}-\frac{q_{t+1}}{R}}$

The dimensionality of the system can be reduced, for instance, substituting the asset price equation into $(28)$ and noting that $q_{t+1}=\frac{g\left(K_{t+1}^{F}\right)}{R}$. In this case the system boils down to:

$$
\begin{aligned}
0= & {\left[\frac{g\left(K_{t}^{F}\right)}{R}-\frac{g\left(K_{t+1}^{F}\right)}{R^{2}}\right] K_{t}^{F}-\left\{(1-\gamma) \alpha\left[1-\frac{A}{(1+\xi) \gamma}\right]+\right.} \\
& \left.+\frac{\gamma g\left(K_{t}^{F}\right)}{R}\right\} K_{t-1}^{F}+(1-\gamma) \frac{A}{(1+\xi) \gamma} G\left(\bar{K}-K_{t-1}^{F}\right),
\end{aligned}
$$

i.e. a second order difference equation in implicit form which describes the motion of the farmer's landholding. The state of the variable in $t+1, K_{t+1}^{F}$, is linked to the state of the same variable in $t$ and $t-1$ in a complicated non-linear way. ${ }^{6}$

From the second equation in (27), it is clear that also the asset price in $t+1, q_{t+1}$, is linked to $K_{t}^{F}$ and $K_{t-1}^{F}$ in a non-linear way.

In the present context $A$ is the policy parameter, which can be modified by the central bank by means of a change of the growth rate of the money supply. From (23) it is immediate to compute $\frac{\partial A}{\partial g_{M}}=\frac{(1+\xi)(1-\gamma) \varphi \xi}{[(1+\xi)(1+\pi)-\varphi \xi]^{2}}>0$.

In the steady state $K_{t}^{F}=K_{t-1}^{F}=K^{F}$ and $q_{t}=q_{t+1}=q$ so that $\mu_{t}=\mu=$ $q \varepsilon$ where $\varepsilon:=1-\frac{1}{R}$. Moreover $\pi_{t+1}=\pi=g_{M}$ so that $\left(1+g_{M}\right) \theta_{t+1}=1$

\footnotetext{
${ }^{6}$ Nevertheless, due to the assumptions on the production function, it is immediate to observe that $K_{t+1}^{F}$ is uniquely defined by (29), being $g($.$) an increasing function.$
} 
and $A=\frac{(1+\xi)(1+\pi) \gamma-\varphi \xi}{(1+\xi)(1+\pi)-\varphi \xi}$. In the steady state the bivariate system composed by (14) and (28) boils down to:

$$
\begin{aligned}
q & =\zeta\left[h\left(K^{F}\right)-\frac{1}{\sigma}+1\right] \\
q & =\frac{g\left(K^{F}\right)}{R} .
\end{aligned}
$$

where:

$$
\begin{aligned}
\sigma & =\frac{A}{(1+\varepsilon) \gamma}, \\
\zeta & =\frac{(1-\gamma) \alpha}{\gamma-\varepsilon} \sigma \\
h\left(K^{F}\right) & =\frac{G\left(\bar{K}-K^{F}\right)}{\alpha K^{F}},
\end{aligned}
$$

and $h^{\prime}\left(K^{F}\right)<0$. Equation (30) represents the isocline of the law of motion of the farmer's land while (31) is the isocline of the asset price equation.

Conditions (30) and (31) determine a system of two equations which can be solved for the steady state values of $K^{F}$ and $q$. Moreover, (31) yields an increasing relationship between $q$ and $K^{F}$ on the $\left(K^{F}, q\right)$ plane. From (30) it is clear that the corresponding isocline can be either upward sloping or downward sloping on the $\left(K^{F}, q\right)$ plane depending upon the relative value of $\gamma$ and $\varepsilon$. In any case, it crosses the x-axis when $\frac{1}{\sigma}+1=h\left(K^{F}\right)$, i.e. when $K^{F}$ reaches a threshold $K_{c}^{F}=h^{-1}(\sigma)$. In the following we will assume $\gamma>\varepsilon$ 7 which seems more plausible on empirical grounds, so that $\zeta>0$ and the curve is downward sloping. Since viability requires that $q>0$, we restrict the analysis to $h\left(K^{F}\right)-\sigma>0$, i.e. $K^{F}<K_{c}^{F}$.

The system is characterized by 7 parameters: the total endowment of land

\footnotetext{
${ }^{7} \gamma>\varepsilon$ implies $R<\frac{1}{1-\gamma}$. Assuming that the real interest rate is equal to $1-2 \%$, this condition is satisfied for a large interval of $\gamma$.
} 
$\bar{K}$, the productivity of the farmer's land $\alpha$, the preference parameter $\gamma$, the real interest rate $R$, the money allocation parameter $\xi$, the cost parameter $\varphi$, the policy parameter $A$.

In order to explore the forward dynamics in (27), we consider as phase variables the asset price $q_{t}$ and the farmer's land, lagged one-period $K_{t-1}^{F}$. Moreover, we specify the gatherer's production function as $G\left(\bar{K}-K_{t}^{F}\right)=$ $\sqrt{\bar{K}-K_{t}^{F}}$. It follows that the dynamics of the macroeconomy are described by the two-dimensional map:

$T:\left\{\begin{array}{l}K_{t}^{F}=\bar{K}-\frac{1}{4 R^{2} q_{t}^{2}} \\ q_{t+1}=R\left[q_{t}-\frac{\left\{(1-\gamma) \alpha\left[1-\frac{A}{(1+\xi) \gamma}\right]+\gamma q_{t}\right\} K_{t-1}^{F}-(1-\gamma) \frac{A}{(1+\xi) \gamma} \sqrt{\bar{K}-K_{t-1}^{F}}}{\bar{K}-\frac{1}{4 R^{2} q_{t}^{2}}}\right]\end{array}\right.$

The first equation of the $T$ map comes from $q_{t}=\frac{g\left(K_{t}^{F}\right)}{R}=1 / 2 R \sqrt{\bar{K}-K_{t}^{F}}$. The second equation can be obtained by rearranging (28). The dynamics generated by (32) implies quite complex nonlinear relations between the two phase variables, involving square root and rational functions. Any analytical approach to the study of its local and global bifurcations appears a hard task, and is beyond the aim of the present paper. We proceed by numerical simulations, leaving to further studies a more accurate analysis.

Depending upon the configuration of parameters, different dynamic patterns can occur. In order to assess the properties of the trajectories generated by (27) we simulate the dynamic system and compute the basin of attractions of the fixed points of the map.

In Figure 1 we represent the phase space $\left(K_{t}^{F}, q_{t}\right)$ when the parameter configuration is the following: $\bar{K}=10, \alpha=1.5, \gamma=0.42, R=1.02$, $\xi=0.022, \varphi=0.47$ and $g_{M}=0.02$. In this scenario, therefore, money growth is rather low $(2 \%)$. Steady state inflation therefore would be correspondingly low. 


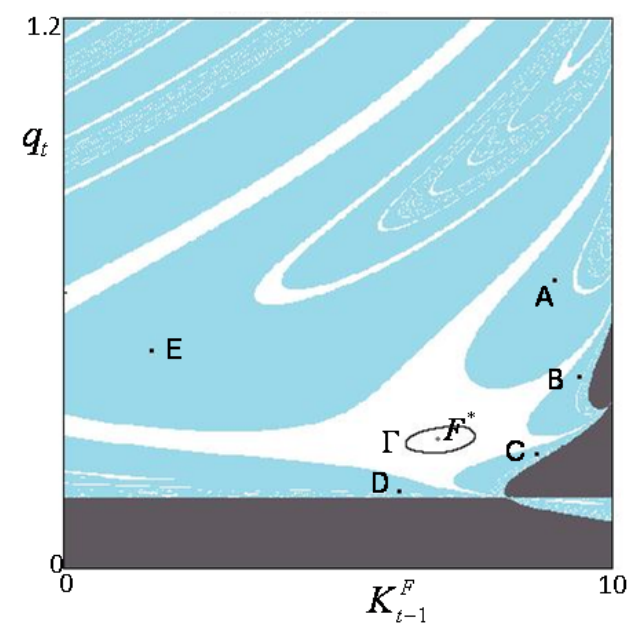

Figure 1: Phase space $\left(K_{t}^{F}, q_{t}\right)$. Parameter configuration: $\bar{K}=10, \alpha=1.5$, $\gamma=0.42, R=1.02, \xi=0.022, g_{M}=0.02$.

Given the above parameter configuration, there exist three points of the map $T$ described in in (32), but only one of them $\left(F^{*} \simeq(6.9135,0.279)\right)$ belongs to the positive ortant of the phase-space. This steady state is a repelling focus. Trajectories starting close to it converge to a closed invariant curve $\Gamma$, which is generated by a supercritical Neimark-Sacker bifurcation of $F^{*}$ when $g_{M} \sim 0.0392$ as shown in Figure 2 panel (b). Quasi periodic or aperiodic orbits emerge when the system "jumps" from one point to another located on the curve. All the points, however, are bound to be visited by trajectories located on the curve. The attracting closed curve $\Gamma$ coexists with a stable cycle of period 5 , having periodic points $\{A, B, C, D, E\}$ (see 
Figure 1) The basins of attraction of the two attractors (white and light grey points) are separated by the stable set of a saddle cycle of period 5 , appeared with the stable one, via a saddle-node bifurcation occurring when $g_{M} \sim 0.09$ (see Figure 2 panel (a)). The evolution of the state variables along the trajectory is clockwise. Finally, the dark grey points are the basin of attraction of divergent trajectories or trajectories characterized by negative (and therefore unfeasible) asset price and/or landholding.

The reason why an oscillating (of a periodic or aperiodic nature) behavior occurs can be explained as follows:

- When the economy jumps from point $E$ to point $A$ on the 5-period cycle or from one point to another belonging to the increasing upper portion of the $\Gamma$ curve, both the asset price and the farmer's landholding increase. This is due to the fact that net worth is going up, making room for investment in land. As time goes by, the increase in landholding leads also to an increase in real money balances - see the third equation in $(27)$ - so that net worth slows down.

- From point $A$ to point $B$ on the 5-period cycle or from one point to another of the decreasing upper portion of the $\Gamma$ curve, the asset price starts falling abruptly while the farmer is still increasing his landholding but at a much slower pace.

- Eventually the farmer's landholding starts decreasing. From point $B$ to point $D$ on the 5-period cycle or from one point to another of the increasing lower portion of the $\Gamma$ curve, both the asset price and the farmer's landholding are going down. Net worth is therefore decreasing.

- As time goes by, the reduction in landholding leads also to a reduction in real money balances so that net worth speeds up. From point $D$ to point $E$ on the 5-period cycle or from one point to another of the decreasing lower portion of the $\Gamma$ curve, the asset price goes up while the farmer's landholding is still going down. 
What happens when the rate of growth of money supply goes up? In Figure 2 panel (a) we have represented the evolution of the 5-period cycle of the asset price as a function of the rate of growth of the money supply keeping the same parameter setting as in Figure 1. The bifurcation diagram has been obtained with initial condition $(9.39,0.42)$.

The amplitude of the cycle is clearly decreasing with the money growth rate. When the rate of growth of money supply reaches a threshold (around $9 \%$ ) the period 5 cycle disappears, as a consequence of a saddle-node bifurcation, and the considered trajectory converges to the steady state. The relation of the 5-period cycle of the farmer's land to the money growth rate (not reported) follows a qualitatively similar pattern.

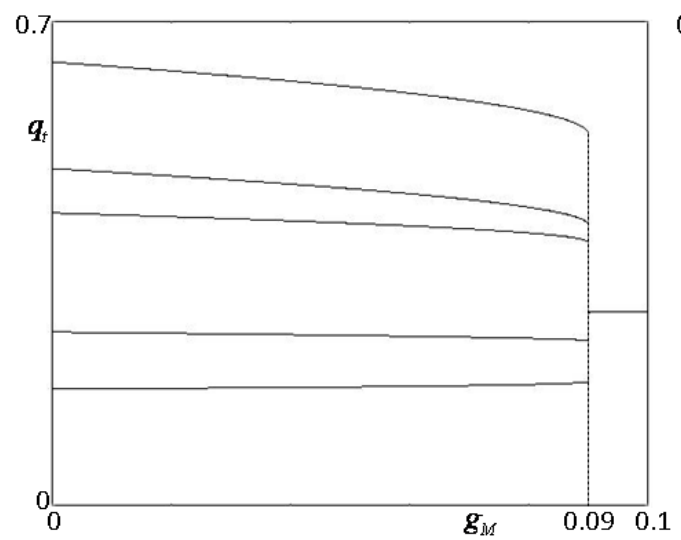

(a)

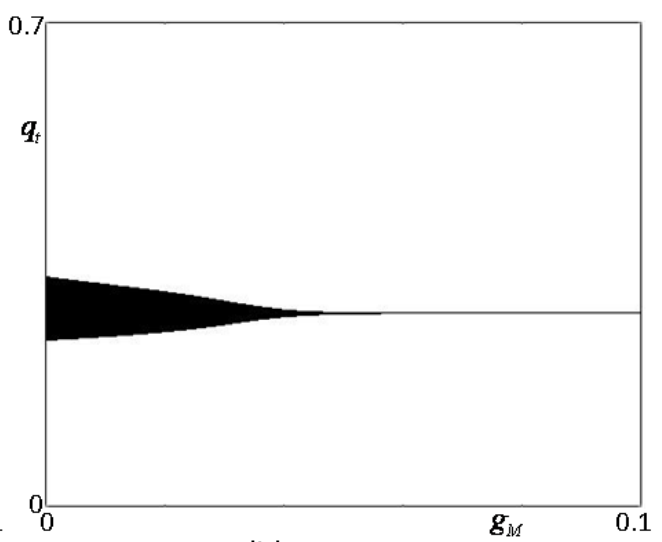

(b)

Figure 2: Bifurcation diagram. (a): 5 period cycle; (b): $\Gamma$ curve 
In Figure 2 panel (b) (obtained with initial conditions 6.3, 0.27) we have represented the evolution of the trajectories on the $\Gamma$ curve of the asset price as a function of the rate of growth of the money supply. The maximum amplitude of the oscillations is clearly decreasing with the money growth rate. When the rate of growth of money supply reaches a critical value close to $4 \%$ the steady state becomes stable, due to the occurring (in reverse way) supecritical Neimark-Sacker bifurcation.

In other words, an expansionary monetary policy has a stabilizing effect. The increase of the rate of growth of money implies that the closed curve shrinks and eventually disappears and the trajectory collapses to a steady state around $4 \%$ of money growth rate. The 5 -periods cycle is still present, coexisting with the steady state, but the amplitude is smaller and smaller. Around $9 \%$ of money growth rate also the 5-period cycle disappears and the trajectory collapses to a steady state. This stabilizing role comes from the negative impact that money holdings have on the accumulation of net worth. In fact net worth is defined as. $\left[(1-\gamma) \alpha+\gamma q_{t}\right] K_{t-1}^{F}-A m_{t, t}^{F}$ where $-A m_{t, t}^{F}=(1-\gamma) m_{t-1, t}^{F}-m_{t, t}^{F}$. Since the parameter $A$ is increasing with the inflation rate, it is straightforward to infer that the higher the inflation rate, the stronger the negative impact of money holdings on net worth and the smaller the overall volatility of the macroeconomy. In our simulations, this result is associated with relatively low inflation rates. We are ruling out on purpose the scenario of hyperinflation which is usually associated with high macroeconomic volatility.

As often occurs in nonlinear models, coexistence of attractors and complex dynamics are possible outcomes. An example of multistability situation has been shown in Figure 1, but it is worth to underline that even more than two attractors may coexist. For instance, at the same parameter constellation of Figure 1, but with $g_{M}=0.087$, the stable fixed point and the period 5 cycle coexist with a cyclical 6-pieces chaotic attractor, obtained through a sequence of period doubling bifurcation of a stable cycle of period 6 , ap- 
peared at $g_{M} \sim 0.1$. In what it follows we describe the emergence of complex dynamics.

In Figure 3 panel (a) we represent the phase space $\left(K_{t}^{F}, q_{t}\right)$ when the parameter configuration is the the same as in Figure 1 but with a slightly smaller real interest rate: $1.5 \%$ instead of $2 \%$. When inflation is high $(12 \%)$ the situation is basically the same as in Figure 1. The unstable steady state coexists with an attracting closed curve and a stable 5-period cycle.

The boundary of the basin of attraction of the closed curve $\Gamma$ is very close to the invariant closed curve (see Figure 3 panel (a)). As the rate of money growth decrease gradually, the occurrence of a contact bifurcation between these two invariant sets (the boundary of the basin and the closed curve) can be detected. Such a bifurcation causes the crisis of the closed invariant curve, that disappears, leaving the cycle of period 5 as the unique attractor at finite distance. As the rate of money growth is further decreased the period-5 cycle undergoes the usual sequence of period doubling bifurcation leading to the strange attractor depicted in Figure 3 panel (b). The final shape of this chaotic attractor is due to a sequence of homoclinic bifurcations associated with different saddle cycles coexisting with the attracting cycles. Indeed, during the period doubling sequence of the period-5 cycle, a cycle of period 3 appears and evolves in a 3-pieces cyclical chaotic attractor, before to disappear through a contact with the boundary of its basin. Obviously, when this 3-band chaotic attractor disappears, infinitely many repelling cycles survive and are responsible of the "explosion" of the chaotic motion.

When $g_{M}$ reaches $4 \%$ a (one-piece) strange attractor appears (see Figure 3 panel (b)). The route to chaotic dynamics, therefore, is based upon a decreasing rate of growth of money supply. If we reverse the argument it is clear that by increasing the rate of growth of money supply, the dynamics simplifies from complex to cycles of aperiodic or periodic nature and possibly to a stable steady state. 


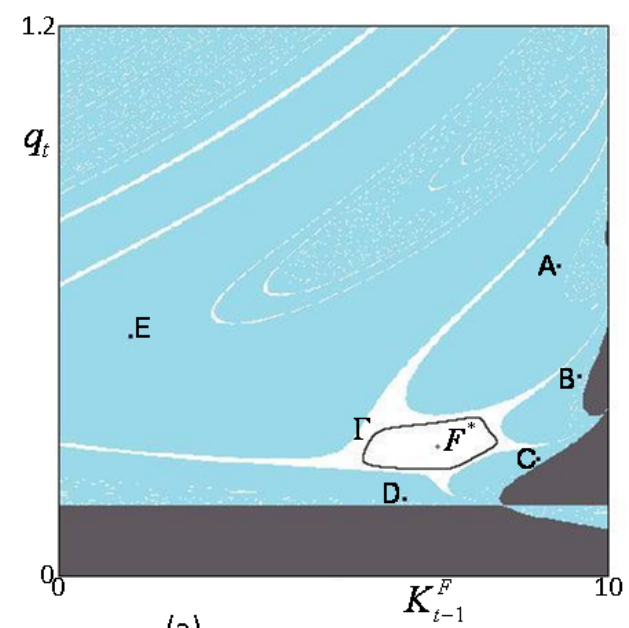

(a)

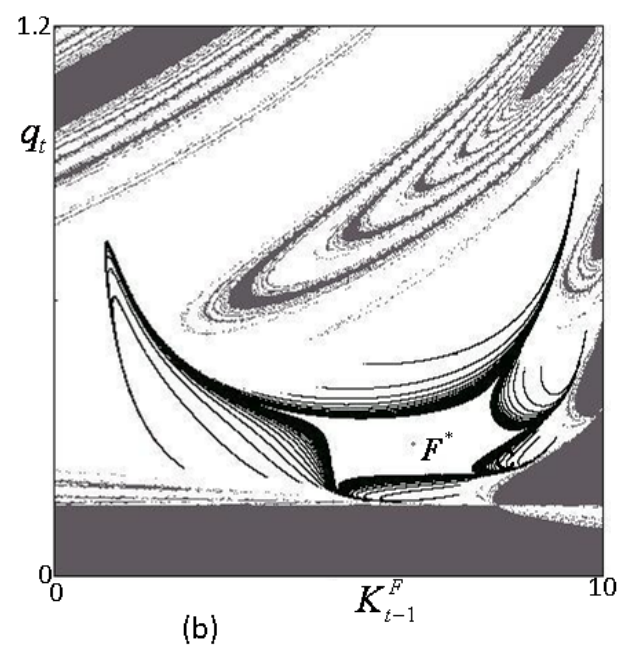

(b)

Figure 3: Phase space $\left(K_{t}^{F}, q_{t}\right)$ as $g_{M}$ decreases we move from panel (a) to panel (b) dynamics.

\section{Related Literature}

We find it rather instructive to compare the dynamics produced by our framework with the one arising under the baseline setting. The original KM model with infinitely lived agents and linear preferences can be summarized by the following dynamic system:

$$
\begin{gathered}
K_{t}^{F}=\frac{a}{\mu_{t}} K_{t-1}^{F}, \\
\mu_{t}=\frac{g\left(K_{t}^{F}\right)}{R_{q_{t+1}}} \\
\mu_{t}=q_{t}-\frac{}{R} .
\end{gathered}
$$


Comparing (33) with (27) we can emphasize four differences. First, the law of motion of the farmer's landholding is richer in an OLG setting. In fact $\left.\frac{d K_{t}^{F}}{d K_{t-1}^{F}}\right|_{O L G}=\frac{(1-\gamma) \alpha+\gamma q_{t}}{\mu_{t}}$ while $\left.\frac{d K_{t}^{F}}{d K_{t-1}^{F}}\right|_{K M}=\frac{a}{\mu_{t}}$. The denominator of the two expressions is the same but the numerator is different. In particular, the numerator of $\frac{d K_{t}^{F}}{d K_{t-1}^{F}}$ in the OLG case is a weighted average of $q_{t}$ and $\alpha .{ }^{8}$ Second, by construction money does not appear in the farmer's landholding equation. Third, the present value of the marginal productivity of the land of the gatherer is equal to the downpayment in KM while it is equal to the asset price in the present context. Fourth, in an OLG setting we can derive a sort of quantity theory of money which can be plugged in the farmer's landholding equation.

In KM dynamics is much simpler. The non-trivial steady state is a saddle point. The authors explore the effects of a sudden change of productivity in a linearized dynamic system obtaining the usual short run and short lived responses to a stochastic shock.

In an appendix, KM sketch an overlapping generations variant of their model along the lines of Blanchard's "finite horizon" framework (Blanchard 1985). This suggestion has been followed by Kasa (1998) who is mainly interested in the welfare analysis and therefore does not focus on the dynamics. The dynamics of Kasa's model, in fact, are not significantly different from those of the original KM framework. The dynamics are richer (but not complex) in the framework put forward by Cordoba and Ripoll (2004) with a cash in advance and a financial constraint.

Pintus et al. (2000), along the lines of Woodford (1986) and Grandmont et al. (1998), explore a model economy populated by two classes of infinitely

\footnotetext{
${ }^{8}$ There is also a minor but non-negligible difference. The production function of the farmer in the original setting is $(a+c) K_{t-1}^{F}$ where $c K_{t-1}^{F}$ is the fraction of output consisting of "bruised fruit" which is non-tradable and is therefore consumed (due to linear preferences) while $a K_{t-1}^{F}$ is tradable output and coincides with the farmer's saving. This distinction is not necessary in the OLG context due to the fact that the utility function is concave. Therefore we write the production function of the farmer as $\alpha K_{t-1}^{F}$.
} 
long-living agents in a perfectly competitive environment under perfect foresight. As in our framework, they envisage a class of financially constrained agents (the workers) as opposed to a class of unconstrained agents, the capitalists. The dynamics generated by the model are characterized by the transition from local regular to global irregular (chaotic) fluctuations in nonlinear dynamic systems in discrete time, a result which generalizes the one shown by de Vilder (1996) in two-dimensional OLG frameworks.

\section{Conclusions}

The present paper can be classified, for the sake of simplicity, in a small but growing body of theoretical literature which emphasizes the long run real effects of inflation in models with financial market imperfection. We model an OLG economy with financing constraints à la Kiyotaki and Moore, money and bequests. We adopt a Diamond-Samuelson approach, a strategy so far not followed in the literature, which has explored only the case of a Blanchard-Yaari framework to model the financial accelerator with overlapping generations (Kasa, 1998).

In this setting we explore the properties of the dynamic two-dimensional system generated by the model. The model can generate a wide range of possible dynamics depending upon parameter configurations. Irregular cyclical trajectories occur over a wide range of plausible parameter constellations. Moreover, under appropriate but not totally unrealistic configurations, a chaotic attractor can also appear.

Changes in the rate of growth of money supply have real effects in the presence of credit frictions. Monetary policy turns out to be non superneutral. When agents face a borrowing constraint, in fact, a redistribution of real assets can occur due to the interaction between net worth and the rate of growth of money supply. 


\section{Acknowledgement}

We would like to thank for helpful comments and discussions the participants to the following meetings: Money, Macro and Finance workshop at the University of York, September 2006, Economic Science with Heterogeneous Interacting Agents at the University of Bologna and Computing in Economics and Finance in Limassol, both in June 2006. 


\section{A Optimization}

In the following we will denote magnitudes at current (constant) prices with capital (small) letters.

Let's examine first the optimization problem of the farmer. The young farmer (YF) is endowed at birth with bequest $A_{t}^{F}$. He employs the bequest and credit $B_{t}$ to invest in land $Q_{t}\left(K_{t}^{F}-K_{t-1}^{F}\right)$ and hold money balances $M_{t, t}^{F}$. The flow-of-funds constraint of the YF in $t$ therefore is:

$$
Q_{t}\left(K_{t}^{F}-K_{t-1}^{F}\right)+M_{t, t}^{F} \leq B_{t}+A_{t}^{F}
$$

Dividing by $P_{t}$ and rearranging we get:

$$
q_{t}\left(K_{t}^{F}-K_{t-1}^{F}\right)+m_{t, t}^{F} \leq b_{t}+a_{t}^{F},
$$

where $q_{t}=\frac{Q_{t}}{P_{t}}, m_{t, t}^{F}=\frac{M_{t, t}^{F}}{P_{t}}, b_{t}=\frac{B_{t}}{P_{t}}, a_{t}^{F}=\frac{A_{t}^{F}}{P_{t}}$.

The $\mathrm{YF}$ is financially constrained. The financing constraint in nominal terms can be expressed as follows:

$$
B_{t} \leq \frac{Q_{t+1}}{1+i_{t}} K_{t}^{F}
$$

where $i_{t}$ is the nominal interest rate. Multiplying and dividing the expression above by $P_{t+1}$ one gets:

$$
b_{t} \leq \frac{q_{t+1}}{R} K_{t}^{F},
$$

where $R:=\left(1+i_{t}\right) /\left(1+\pi_{t+1}\right)$ is the real (gross) interest rate and $1+\pi_{t+1}:=$ $P_{t+1} / P_{t}$ is the (gross) rate of inflation. $R$ is given and constant $^{9}$.

In $t$, the YF uses labour and land $K_{t}^{F}$ to produce output $y_{t+1}^{F}$ which will become available in $t+1$. When old, the farmer employs output and money balances $M_{t, t+1}^{F}$ to reimburse debt, consume and leave a bequest. Therefore

\footnotetext{
${ }^{9}$ This assumption holds if the current nominal interest rate is adjusted for future inflation as follows $i_{t}=(R-1)+R \pi_{t+1}$.
} 
the flow of funds constraint of the old farmer (OF) in $t+1$ in nominal terms is:

$$
P_{t+1} c_{t, t+1}^{F}+A_{t+1}^{F}+B_{t}\left(1+i_{t}\right) \leq P_{t+1} y_{t+1}^{F}+M_{t, t+1}^{F}
$$

Dividing by $P_{t+1}$, recalling that $y_{t+1}^{F}=\alpha K_{t}^{F}$ we obtain:

$$
c_{t, t+1}^{F}+a_{t+1}^{F}+R b_{t} \leq \alpha K_{t}^{F}+m_{t, t+1}^{F}
$$

The farmer maximizes (7) subject to (34), (35) and (36). The Lagrangian is

$$
\begin{aligned}
\mathcal{L}= & \gamma \ln c_{t, t+1}^{F}+(1-\gamma) \ln a_{t+1}^{F}+\nu^{F} m_{t, t}^{F}+\lambda_{t}^{F}\left[b_{t}+a_{t}^{F}-q_{t}\left(K_{t}^{F}-K_{t-1}^{F}\right)-m_{t, t}^{F}\right]+ \\
& +\lambda_{t+1}^{F}\left[\alpha K_{t}^{F}+m_{t, t+1}^{F}-c_{t, t+1}^{F}-a_{t+1}^{F}-b_{t} R\right]+\phi_{t}\left[\frac{q_{t+1}}{R} K_{t}^{F}-b_{t}\right]
\end{aligned}
$$

The FOCs are

$$
\begin{aligned}
& (i F) \frac{\partial \mathcal{L}}{\partial c_{t, t+1}^{F}}=0 \Rightarrow \frac{\gamma}{c_{t, t+1}^{F}}=\lambda_{t+1}^{F} \\
& (i i F) \frac{\partial \mathcal{L}}{\partial a_{t+1}^{F}}=0 \Rightarrow \frac{1-\gamma}{a_{t+1}^{F}}=\lambda_{t+1}^{F} \\
& (i i i F) \frac{\partial \mathcal{L}}{\partial m_{t, t}^{F}}=0 \Rightarrow \nu^{F}-\lambda_{t}^{F}=0 \\
& (i v F) \frac{\partial \mathcal{L}}{\partial b_{t}}=0 \Rightarrow \lambda_{t}^{F}-\lambda_{t+1}^{F} R=\phi_{t}
\end{aligned}
$$

From $(i F)$ and $(i i F)$ follows that $\lambda_{t+1}^{F}=\frac{\gamma}{c_{t, t+1}^{F}}=\frac{1-\gamma}{a_{t+1}^{F}}>0$. Hence the flow of funds of the $\mathrm{OF}$ is binding. Taking into account $(i F)$, from $(i i i F)$ follows $\lambda_{t}^{F}=\nu^{F}>0$. Also the flow of funds of the YF is binding. Finally, we assume that

$$
\frac{\lambda_{t}^{F}}{\lambda_{t+1}^{F}}>R
$$

so that from $(i v F)$ follows that $\phi_{t}>0$. Therefore the financing constraint is 
binding.

Using the FOCs and the constraints it is easy to conclude that $c_{t, t+1}^{F}=$ $\gamma e_{t+1}^{F}$ and $a_{t+1}^{F}=(1-\gamma) e_{t+1}^{F}$ where $e_{t+1}^{F}=\left(\alpha-q_{t+1}\right) K_{t}^{F}+m_{t, t}^{F}\left(1+g_{M}\right) \theta_{t+1}$ are the resources available to the OF. Hence

$$
\lambda_{t+1}^{F}=\frac{\gamma}{c_{t, t+1}^{F}}=\frac{1-\gamma}{a_{t+1}^{F}}=\frac{1}{e_{t+1}^{F}} .
$$

In words, the marginal utility of consumption is equal to the marginal utility of bequest and is equal to the reciprocal of the resources available to the OF.

Substituting the values of the Lagrange multipliers into (37) we can rewrite it as

$$
\frac{\lambda_{t}^{F}}{\lambda_{t+1}^{F}}=\nu^{F} e_{t+1}^{F}>R
$$

or

$$
\nu^{F}>\frac{R}{e_{t+1}^{F}}=\frac{R}{\left[\left(\alpha-q_{t+1}\right) K_{t}^{F}+m_{t, t+1}^{F}\right]}=\hat{\nu}^{F} .
$$

The condition above - which implies that $\phi_{t}>0$ and the financing constraint is binding - will be always satisfied the marginal utility of money must be sufficiently high, i.e. higher than a threshold $\hat{\nu}^{F}>0$ for (38) to hold. In the steady state the condition above boils down to

$$
\nu^{F}>\frac{R}{\left[\left(\alpha-q_{s}\right) K_{s}^{F}+m_{s}^{F}\right]}
$$

Let's consider now the gatherer's optimization problem. The young gatherer (YG) is endowed at birth with bequest $A_{t}^{G}$ which he employs to extend credit $B_{t}$, invest in land $Q_{t}\left(K_{t}^{G}-K_{t-1}^{G}\right)=-Q_{t}\left(K_{t}^{F}-K_{t-1}^{F}\right)$ and hold money balances $M_{t, t}^{G}$. The flow of funds constraint of the YG in $t$ is

$$
Q_{t}\left(K_{t}^{G}-K_{t-1}^{G}\right)+B_{t}+M_{t, t}^{G} \leq A_{t}^{G}
$$


Dividing by $P_{t}$ we get

$$
q_{t}\left(K_{t}^{G}-K_{t-1}^{G}\right)+b_{t}+m_{t, t}^{G} \leq a_{t}^{G}
$$

In $t$, the YG uses labour and land $K_{t}^{G}=\bar{K}-K_{t}^{F}$ to produce output $y_{t+1}^{G}$ which will become available in $t+1$. When old, the gatherer employs the output, the repayment of the loan extended when young and money to consume and leave a bequest. He also has to incur the transaction cost $C M F_{t}^{G}=\varphi M_{t, t}^{G}$. Therefore the flow of funds constraint of the OG in $t+1$ is

$$
P_{t+1} c_{t, t+1}^{G}+A_{t+1}^{G}+C M F_{t}^{G} \leq P_{t+1} y_{t+1}^{G}+B_{t}\left(1+i_{t}\right)+M_{t, t+1}^{G} .
$$

Dividing by $P_{t+1}$ and recalling that $y_{t+1}^{G}=G\left(K_{t}^{G}\right)$ and $\frac{M_{t, t+1}^{G}}{P_{t+1}}=m_{t, t+1}^{G}$ we get

$$
c_{t, t+1}^{G}+a_{t+1}^{G}+C M F_{t}^{G} \leq G\left(K_{t}^{G}\right)+q_{t+1} K_{t}^{F}+m_{t, t+1}^{G} .
$$

The gatherer maximizes (15) subject to (39) and (40). The Lagrangian is

$$
\begin{aligned}
\mathcal{L}= & \gamma \ln c_{t, t+1}^{G}+(1-\gamma) \ln a_{t+1}^{G}+\nu^{G} m_{t, t}^{G}+\lambda_{t}^{G}\left[a_{t}^{G}-q_{t}\left(K_{t}^{G}-K_{t-1}^{G}\right)-m_{t, t}^{G}-b_{t}\right] \\
& +\lambda_{t+1}^{G}\left[G\left(K_{t}^{G}\right)+q_{t+1} K_{t}^{F}+m_{t, t+1}^{G}-c_{t, t+1}^{G}-a_{t+1}^{G}-C M F_{t}^{G}\right] .
\end{aligned}
$$


The FOCs are

$$
\begin{aligned}
(i G) \frac{\partial \mathcal{L}}{\partial c_{t, t+1}^{G}} & =0 \Rightarrow \frac{\gamma}{c_{t, t+1}^{G}}=\lambda_{t+1}^{G} \\
(i i G) \frac{\partial \mathcal{L}}{\partial a_{t+1}^{G}} & =0 \Rightarrow \frac{1-\gamma}{a_{t+1}^{G}}=\lambda_{t+1}^{G} \\
(i i i G) \frac{\partial \mathcal{L}}{\partial m_{t, t}^{G}} & =0 \Rightarrow \nu^{G}-\lambda_{t}^{G}=0 \\
(i v G) \frac{\partial \mathcal{L}}{\partial K_{t}^{G}} & =0 \Rightarrow \lambda_{t+1}^{G} G^{\prime}\left(K_{t}^{G}\right)=\lambda_{t}^{G} q_{t} \\
(v G) \frac{\partial \mathcal{L}}{\partial b_{t}} & =0 \Rightarrow \lambda_{t}^{G}=\lambda_{t+1}^{G} R
\end{aligned}
$$

From $(i G)$ and $(i i G)$ follows that $\lambda_{t+1}^{G}=\frac{\gamma}{c_{t, t+1}^{G}}=\frac{1-\gamma}{a_{t+1}^{G}}>0$. Hence the flow of funds of the $O G$ is binding.

From $(v G)$ follows that

$$
\frac{\lambda_{t}^{G}}{\lambda_{t+1}^{G}}=R
$$

so that

$$
\lambda_{t}^{G}=\lambda_{t+1}^{G} R=\frac{\gamma}{c_{t, t+1}^{G}} R=\frac{1-\gamma}{a_{t+1}^{G}} R>0 .
$$

Hence also the flow of funds of the YF is binding.

Using the FOCs and the constraints it is easy to conclude that $c_{t, t+1}^{G}=$ $\gamma e_{t+1}^{G}$ and $a_{t+1}^{G}=(1-\gamma) e_{t+1}^{G}$ where $e_{t+1}^{G}=G\left(K_{t}^{G}\right)+q_{t+1} K_{t}^{F}+m_{t}^{G}\left(1+g_{M}-\varphi\right) \theta_{t+1}$ are the resources available to the OG. Hence $\lambda_{t+1}^{G}=\frac{\gamma}{c_{t, t+1}^{G}}=\frac{1-\gamma}{a_{t+1}^{G}}=\frac{1}{e_{t+1}^{G}}$. Using the equality above, the From FOC $(i i i G)$ Lagrange multiplier $\lambda_{t}^{G}$ turns out to be

$$
\lambda_{t}^{G}=\nu^{G}
$$

Substituting the above condition into (41) and recalling that $\lambda_{t+1}^{G}=\frac{1}{e_{t+1}^{G}}$ we 
get

$$
\frac{\lambda_{t}^{G}}{\lambda_{t+1}^{G}}=\nu^{G} e_{t+1}^{G}=R
$$

Comparing the FOCs of the optimization problem of the farmer with those of the gatherer we can draw the following conclusion

$$
\frac{\lambda_{t}^{F}}{\lambda_{t+1}^{F}}=\nu^{F} e_{t+1}^{F}>\frac{\lambda_{t}^{G}}{\lambda_{t+1}^{G}}=\nu^{G} e_{t+1}^{G}=R
$$

This conclusion was true also in KM but with a different meaning. In fact in a KM-ILA economy $\frac{\lambda_{t}^{F}}{\lambda_{t+1}^{F}}=\frac{1}{\beta^{F}}>\frac{\lambda_{t}^{G}}{\lambda_{t+1}^{G}}=\frac{1}{\beta^{G}}=R$. Hence this condition reflected preference heterogeneity.

Finally, from $(i v G)$ and $(v G)$ follows (14)

$$
q_{t}=\frac{G^{\prime}\left(K_{t}^{G}\right)}{R}
$$




\section{References}

Blanchard, O., 1985. Debt, deficits, and finite horizons. Journal of Political Economy 93, 223-247.

Boyd, J., Smith, B., 1998. Capital market imperfections in a monetary growth model. Economic Theory 11, 241-273.

Bullard, J., Keating, J., 1995. The long-run relationship between inflation and output in postwar economies. Journal of Monetary Economics 36, 477-496.

Cordoba, M., Ripoll, J. C., 2004. Collateral constraints in a monetary economy. Journal of the European Economic Association 2, 11721205.

de Vilder, R. G., 1996. Complicated endogenous business cycles under gross substitutability. Journal of Economic Theory 71, 416-442.

Grandmont, J.M., Pintus, P., de Vilder, R., 1998. Capital-labor substitution and competitive nonlinear endogenous business cycles. Journal of Economic Theory 80, 14-59.

Grandmont, J.M., Younes, Y., 1973. On the efficiency of a monetary equilibrium. Review of Economic Studies 40, 149-165.

Kasa, K., 1998. Borrowing constraints and asset market dynamics: evidence from the pacific basin. Federal Reserve Bank of San Francisco Economic Review 1998, 17-28.

Kehoe, T.J., Levine, D.K., Woodford, M., 1992. The optimum quantity of money revisited. In: Dasgupta, P., Gale, D., Hart, O., Maskin, E. (Eds.). Economic Analysis of Markets and Games. Cambridge, MA: The MIT Press, 501-526.

Khan, M., Senhadji, A., Smith, B., 2001. Inflation and financial depth. IMF Working Paper WP/01/04. 
Kiyotaki, N., Moore, J., 1997. Credit cycles. Journal of Political Economy 105, 211-248.

Loayza, N., Schmidt-Hebbel, K., Servén, L., 2000. What drives private saving across the world. The Review of Economics and Statistics 82, 165-181.

Pintus, P., Sands, D., de Vilder, R., 2000. On the transition from local regular to global irregular fluctuations. Journal of Economic Dynamics and Control 24, 247-272.

Ragot, X., 2006. A theory of low inflation with credit constraints. mimeo. Available at http://www.pse.ens.fr/ragot/lowinflation9.pdf

Weil, P., 1991. Is money net wealth? International Economic Review $32,37-53$.

Weiss, L., 1980. The effects of money supply on economic welfare in the steady state. Econometrica 48, 565-576.

Woodford, M., 1986. Stationary sunspot equilibria in a finance constrained economy. Journal of Economic Theory 40, 128-137. 